Peer-Reviewed Article

ISSN: 2162-3104 Print/ ISSN: 2166-3750 Online

Volume 5, Issue 4 (2015), pp. 368-382

(C) Journal of International Students

http://jistudents.org/

\title{
Exploring the Motivations, Expectations, and Experiences of Students Who Study in Global Settings
}

\author{
Vince Salyers, EdD \\ Cathy S. Carston, $\mathrm{PhD}$ \\ Yasmin Dean, $\mathrm{PhD}$ \\ Chad London, $\mathrm{PhD}$ \\ Mount Royal University, Canada
}

\begin{abstract}
An increasing trend of universities is to provide students with opportunities to engage in global learning experiences (GLE) as part of their program of study. While there are numerous papers on the benefits of international and study abroad programs, there is little research on factors that impact GLE. This study evaluated the student perspective through qualitative and quantitative responses to surveys and questions posed during a period of three years. The results suggested that students' motivation and expectations of the experiences were varied. Moreover, planning is critical for GLE experiences to have a positive impact on students.
\end{abstract}

Keywords: global education; student motivation; student expectations; experiences

Most universities around the world are providing increased opportunities for students to participate in education experiences across the globe (Altbach \& Knight, 2007; Altbach, Reisberg, \& Rumbley, 2009; Belyavina, Li, \& Bhandari, 2013; Dwyer, 2004; Farrugia, Bhandari, \& Chow, 2012; Gammonley, Rotabi, \& Gamble, 2007; Salisbury, Paulsen \& Pascarella, 2009). Studies have shown that university students who participate in study abroad programs may develop improved cultural sensitivity, language proficiency, personal growth, openness to diversity, and enhanced civic responsibility as the result of these experiences (Clarke, Flaherty, Wright, \& McMillen, 2009; Ingraham \& Peterson, 2005; Fry, Paige, Jon, Dillow, \& Nam, 2009; Gilin \& Young, 2009; Mapp, 2012; Mapp, McFarland, \& Newell, 2007; Rhodes, Biscarra, Loberg \& Roller, 2012).

Moreover, an emerging perspective from the literature emphasizes the importance of creating an experience that has reciprocal benefits for both the students and the international host agency (Alphonse, 2008; Hanson, Harms, \& Plamondon, 2010; Heron, 2006; Lough, 2009; Memmot, Converston, Heise, Williams, Maughan, Kohl, \& Palmer, 2010; Razack, 2002). In order to enhance the experiences of students and host agencies, global learning experiences September/October 2015 http://jistudents.org

Volume $5 \cdot$ Issue 4 
(GLE) should emphasize meaningful role taking, support, and reflection (Deardorrf, 2008). Critical activities such as reflection and critical analysis are not readily available in many current programs (Heron, 2006; Tiessen, 2008; Wehbi, 2009).

At the university where this study was conducted, numerous consultation sessions occurred with students who are involved in GLE. As a result of these consultations, three key factors: motivations, expectations, and pre-departure preparation emerged as areas of exploration related to GLE. Although the benefits of study abroad and global education programs are many, there is scarce research on these three factors and their impact on GLE. This study provided important insights related to these factors and made evidence-informed recommendations to better structure and support GLE.

\section{Literature Review}

\section{Participation in GLE}

In the past ten years, minimal research was identified that determined reasons why students participated in GLE and their motivations for doing so (Chew \& Croy, 2011; Daly, 2011; Goldstein \& Kim, 2006; Salisbury, Paulsen \& Pascarella, 2009; Schnusenberg \& de Jong, 2012; Webhi, 2009). Researchers have concluded that students participate in GLE for a variety of reasons including personal dispositions, interest in other cultures, travel to other countries, language acquisition, and opportunities for career, professional development, and pleasure (Allen, 2010; Chew \& Croy, 2011; Daly, 2011; He \& Chen, 2010; Kuzma, Kuzma \& Thiewes, 2012; Relyea, Cocchiara, \& Studdard, 2008; Schnusenberg \& de Long, 2012; Stroud, 2010; Toncar, Reid \& Anderson, 2005; Trilokekar \& Rasmi, 2011; Zemach-Bersin, 2009). Factors that result in non-participation in GLE include financial constraints, language constraints, and personal safety (Daly, 2011; Kuzma, Kuzma, \& Thiewes, 2012; Trilokekar \& Rasmi, 2011).

\section{Student Expectations}

Research has indicated that students who participate in GLE may find their expectations not fully fulfilled and are often different from what they originally anticipated. Among the many expectations students may hold prior to the GLE, foreign language acquisition, exposure and immersion to other cultures, application of classroom concepts, and enhanced employment opportunities are mentioned frequently (Amuzie \& Winkle, 2009; Badstübner \& Ecke, 2009; Brown \& Aktas, 2012).

\section{Pre-Departure Planning}

Research on essential components of pre-departure planning for GLE is fairly limited. Linder and McGaha (2013) suggested that pre-departure planning should begin a minimum of one year in advance of travel; and recommended reconnaissance trips by faculty to explore global sites and establish relationships with host agencies. Moreover, they strongly encouraged well-defined recruitment strategies and the provision of a number of pre-departure meetings to prepare students for travel. Researchers have suggested that pre-departure sessions should prepare students for the practicalities of travel abroad (e.g. food, culture, personal safety, learning and traveling together) so that the sessions may better prepare them for their global learning experiences (Kruse \& Brubaker, 2007; Schwieter \& Kunert, 2012).

The purpose of this study is to inform and improve GLE practices. To guide the study, the following research questions were posed: 
1. What are the motivations of students who engage in GLE?

2. What are the expectations of students who engage in GLE?

3. What impact does the pre-departure orientation process have on student experiences?

\section{Institutional Context}

This research was carried out in two phases within a mid-sized university in Western Canada, with a total enrollment of approximately 13,570 students. The researchers are faculty members from four departments and one school representing the disciplines of Child and Youth Studies, Nursing, Physical Education and Social Work. They share the common philosophical and inter-professional perspectives related to importance and need to provide GLE for students. Within this research team, researchers work closely with their deans on the GLE proposal and curricular content, while the Office of International Education supports budgeting, fee collection and risk management planning for faculty who lead these experiences and the students who participate. For the context of this study, GLE includes exchanges, field schools, practice and other experiential learning activities carried out in global settings.

Planning for GLE includes the development of learning activities and assessments, travel budgets, itineraries, communication with host agencies and partners, and completion of institutional risk management documentation. For most GLE at the university where this study was conducted there is a ratio of one faculty for ten students; when more than one faculty participated, up to 25 students are allowed to participate. For supervised practical coursework and experiential courses faculty to student ratios may be mandated by professional organizations and regulatory bodies.

Students are generally recruited for GLE at least 12 months in advance of travel and, in some instances, as many as two years prior to the initiative. Student recruitment and selection procedures consist of interviews, critical reflections regarding why s/he would like to participate, professor references and academic performance. Once students have been selected, the lead researcher meets with students regularly to begin preparations for the experience.

The Office of International Education oversees the collection of student fees, coordination of travel insurance and risk management documentation, and then conducts general pre-departure orientation sessions. Pre-departure orientation sessions for students include general information related to international travel, immunizations, and safety preparation. Faculty who lead a GLE provide course or discipline specific information.

\section{Research Methods}

This multi-phase, mixed methods study used a concurrent triangulation design to guide and facilitate data collection. In this approach, quantitative and qualitative data are collected at designated points and triangulated (Creswell, 2009; Creswell, Plano Clark, Gutmann, \& Hanson, 2003). Data are compared in order to identify similarities, differences, gaps, and unanswered questions. Triangulation of the data increased trustworthiness (Creswell, 2009; Johnson \& Waterfield, 2004; Li, 2004) and provided for a more robust and comprehensive understanding of the data that was obtained. 


\section{Participant Selection and Ethics}

No inclusion or exclusion criteria were used in the study. All students who had participated in a GLE in 2012, 2013, and 2014 were invited to voluntarily participate. No risks or ethical concerns were identified as part of the ethics review process. Approval to conduct research with human subjects was obtained from the Human Research Ethics Board (HREB) prior to data collection.

\section{Methods for Phase I}

The first phase of this study explored the first two research questions using survey and active interviewing techniques with a small sample of students. The central themes explored were the participants' experiences and motivations of their involvement with the GLE. Three sources of data were collected as part of this phase. Responses to online surveys distributed prior to departure (source \# 1) and upon return from the international experience (source \# 2) were collected. Demographic and qualitative data were collected through the survey process. Survey questions included the solicitation of information about the application, selection, orientation processes, as well as explored student motivations, learning goals and needs. During 2012, students ( $\mathrm{n}=32 ; 24 \%$ response rate) traveling to Australia, England, India, Malaysia, Mexico, New Zealand, Peru, Qatar, and Sri Lanka received the online questionnaire prior to and immediately following their international study experience regarding their motivations, expectations and pre-travel preparation related to the GLE.

Additionally, all students were invited to participate in active interviews (source \# 3), of which 11 participated upon their return. The active interview (Holstein \& Gubrium, 1995) was carried out in the form of individual interviews and focus group sessions; exploring in greater depth responses received to questions that were posed in the survey.

\section{Data Analysis}

Initially, the data were sent to a statistician who used NVivo 9.0 to independently code all the data. Once the data were coded, themes and sub-themes were generated and forwarded to the researchers. Following this step and as part of a data triangulation process, each researcher reviewed focus group transcripts and online surveys independently and compared them to themes and sub-themes provided by the statistician to validate the data.

Utilizing a thematic process outlined by Miles \& Huberman (1994), the data were analyzed by the researchers using a three-step approach: (1) data reduction, whereby participants' responses were sorted into clusters of varying main themes; (2) data display, whereby participants' responses were organized, compressed, and assembled into various tables and figures, which assured conclusions to be readily visible and easily drawn; and (3) conclusion drawing/verification, whereby conclusions were deemed trustworthy, credible and reliable through the use of repeated group readings of participants' responses, multiple group discussions, and debate (Carter, Horrigan, \& Hudyma, 2010).

\section{Results - Phase I}

To answer research questions \# 1 and \# 2, emerging themes identified by the researchers related to three research variables (motivations, expectations, and pre-travel preparation) are described in the following sections. 


\section{Motivations}

Students reported practical motivations for participating in GLE. Their responses acknowledged opportunities for "hands on" career development, language, and cultural knowledge acquisition. These themes were consistent with those from the literature (Clarke, Flaherty, Wright, \& McMillen, 2009; Ingraham \& Peterson, 2005; Fry, Paige, Jon, Dillow, \& Nam, 2009; Gilin \& Young, 2009; Mapp, 2012; Mapp, McFarland, \& Newell, 2007; Rhodes, Biscarra, Loberg \& Roller, 2012) as reasons why students participate in GLE.

Students identified participation in GLE courses as a unique opportunity to combine firsttime travel with study abroad and indicated this was a strong motivation for them to participate. Students believed they would not have been exposed to this type of experiential learning if the GLE had not been led by a faculty. As one participant stated, "I figured ... what are the chances of my ever getting an opportunity [like this] again? It is a learning experience, a cultural experience, there is a little bit of travelling - which I hadn't had a chance to do". Although many students with little or no experience with GLE may be highly motivated to participate, it is important to develop recruitment and selection processes that take this inexperience into consideration and balance it with their motivations to participate.

Encouragement and support from faculty, peer and family were also frequently mentioned as important reasons why students were motivated to apply and participate in GLE. Encouragement from professors and conversations and planning with other participating peers were noted as strong contributors to students' motivation.

Students also agreed that emotional and financial support from their families was highly influential in making decisions to study in global settings. Moreover, students described how important these supports were to their success with a particular global experience. One student's perspective was,

I am lucky that way, my family is very supportive. I still have to pay for the trip on my own, [although] my parents basically up-fronted [sic] the money for me and I can pay them back as I have money. I think that was definitely a big thing as it is very expensive ... but I definitely think it was worth it.

Some students discussed the value of gaining course credits while also having the opportunity to travel as a strong motivator. Not only was this a hands-on experience, it would also reduce course loads in a subsequent term. The consensus from a number of students was that time was a stronger motivation factor for participation than the additional expense of travel. As one participant expressed, this was a great opportunity to "knock off a course or two", therefore reducing her workload for the next term.

\section{Expectations}

Students described a range of expectations from the global experience in phase I of the study. This included excitement and some anxiety about not knowing what to expect. They anticipated concerns about physical and emotional discomforts, fear of the unknown related to potential language barriers, culture shock and group dynamics. They identified the need to "push oneself," yet also seemed surprised when these expectations came to fruition. As one participant described, "I was expecting to be challenged emotionally, and I expected to be put outside my comfort zone. I knew that it would be hot - and it was - [but] I wasn't expecting what that would do to my body". 
Consistent with cited literature, (Clarke, Flaherty, Wright, \& McMillen, 2009; Ingraham \& Peterson, 2005; Fry, Paige, Jon, Dillow, \& Nam, 2009; Gilin \& Young, 2009; Mapp, 2012; Mapp, McFarland, \& Newell, 2007; Rhodes, Biscarra, Loberg \& Roller, 2012), students expected to develop personal and social awareness from their international experiences. Heron (2005) suggested “...analysis of personal experiences can enable students to consolidate a less self-centered perspective on their international placements and in the process integrate the experience into their conceptualization of social justice (p. 271)". This included learning about group dynamics cultural sensitivity, risk-taking, negotiation, self-confidence, patience and tolerance. For example, one participant shared,

I have to say that I learned that 'love' is a need. I have heard it [before], and now I have learned it.... How fortunate we are that women are treated equally to men; that if you are born a girl, you can actually have a life and you are not put in a dumpster - literally - that you have an option for education.

Another student shared, "[I thought] they were not going to respect me because of my age,' but...if you just put yourself out there, it pays off'. Numerous comments made by students reflect similar themes and perspectives and mirror the impact that experience and learning in global settings might provide. Some students, however, expressed high expectations and enthusiasm, envisioned a guided and safe travel experience facilitated by faculty, desired opportunities for networking, and broadened cultural sensitivity. These types of expectations seemed to be influenced by their prior experience (travel and discipline related) and predeparture preparation experience.

\section{Pre-Departure Influences}

Students' frequently mentioned the influence of their pre-travel preparation, both within the surveys and during the active interviews. At the university where the study was conducted, advisors, practicum coordinators, faculty, administrators, and financial assistants contributed to the pre-travel planning process. Students articulated the challenges with communication when numerous individuals were involved. While there are clear processes outlined for students related to GLE, invariably conflicting messages between students, faculty and others were frequently mentioned by students as problematic. There was a general agreement among students that a well-organized application and selection process that included fair and clear communication from the Office of International Education, the faculty leader, and other key individuals was required. As one participant described, "We had a lot of bumps and bruises along the way... communication ...was very bumpy and it kind of felt like we were out of the loop". Further, students indicated that inconsistency of the communication and information exchanges impacted their learning and overall experience.

In many universities and institutions, pre-travel orientation sessions include the provision of general information regarding travel abroad, risk mitigation, immunization and vaccination requirements, finances, as well as other pertinent information related to global travel (Linder \& McGaha, 2013). For students in this study the orientation experience proved to be the most critical factor associated with a successful GLE. When meetings or seminars with the faculty leader were held regularly prior to the trip, students responded very positively, indicating that they felt well-prepared. They also indicated that they had a good understanding of what was expected of them and began to develop a positive relationship with their classmates which had an overall influence on group dynamics. As one participant described, 
Once a month, we had sessions to prepare us for what we were getting into. We had Skype chats [between] the director of the ashram and the university [where we talked] about project ideas. [These] group sessions [let us] know who we were travelling with, and so that was great!

At the institution where the study occurred, there are a number of recruitment and selection processes to determine whether or not students would participate in the GLE. Many authors describe the importance of choosing students who are good fit for an international placement and who will benefit educationally and professionally from such an experience (Lough, 2009; Memmot, et al. 2010; Razack, 2002). Memmot et al. (2010) emphasized the importance of selection criteria as part of the process by stating, "It is important to select students according to several criteria, namely adequate ... knowledge and skills, interpersonal skills, cultural sensitivity, maturity and flexibility (p. 301)".

In some universities, a student's prior travel experience may be identified as highly desired criteria by which to make selection decisions. Selection criteria that consider previous travel experience may be one means for identifying which students may be a risk for an unsuccessful GLE and may mitigate some of the potential challenges they face. As an example, in some academic departments at the university where this study was undertaken, the qualified applicants are selected through a fairly expeditious process based on predetermined criteria such as grade point average and pre-screening of applications. In other departments, in addition to predetermined selection criteria, the applicant may be requested to write an essay and participate in an interview as part of the selection process. This process and decision can take up to several months.

Another shared expectation among the students was the need for consistent processes and the timely exchange of information. This, coupled with the need for a standardized orientation process that provides students with sufficient pre-travel information is essential for a high quality international learning experience. One student summarized the need for well-designed application, selection, and orientation processes by suggesting "we start making the [organizational] process a whole lot cleaner and more streamlined-much earlier [in the preparation phase]."

The opportunity to prepare students as much as possible regarding language, culture, and the academic and professional expectations upon arrival can be influential to their success during their GLE placement. It is also important that they reflect on their experience post departure (Birkbeck \& Bava, 2007; Heron, 2006; Lough, 2009; Memmot et al. 2010; Razack, 2002). Students in this study concurred that a certain level of language proficiency when travelling in areas where their first language was not spoken was essential. For instance, a small group of students participated in a 10-week session to gain a greater understanding of the Malaysian culture and language. These students reported that although they studied some common words and phrases prior to travel, they would have learned more if they had greater language preparation prior to leaving. A consistent experience described by all students was the difficulty in finding time and financial resources to develop country-appropriate language skills. One student stated, "[Office of International Education] requires a level one Spanish course before you go to any Spanish speaking countries and that simply wasn't possible for [us]given our current workload and course load". 
In another situation, some of the participants in this study traveled to India as part of a field school. While proficiency in the Hindi language might have facilitated aspects of the international experience, ultimately the learning experience was about being immersed in the culture and did not necessarily require that students spoke Hindi as part of course. While students may have difficulties in developing language proficiency for the reasons previously identified, the researchers believe, optimally, that some beginning language proficiency of some participants would be a helpful requirement in settings where English is not the first language. The authors do acknowledge, however, that this is not always possible. Table 1 summarizes student themes based on triangulation of responses to the three data sources.

\section{Table 1. Student Themes from Phase I}

\section{Motivational Factors for Participating}

- Social (e.g. encouragement from faculty, peers and family, challenge self, explore values)

- Professional (e.g. resume/career development

- Educational (e.g. course credit, handson experience)

- Cultural (e.g. language acquisition, different cultures $\&$ perspectives)

\section{Admission and Orientation Influences}

- The importance of clear communication and preparation

- The value of language and cultural knowledge prior to travel

\section{Expectations for the Experience}

- Emotional challenges (e.g. group dynamics, culture shock, discomfort, awkwardness, etc.)

- Education (e.g. hands-on and practical skills development; "real world" application of content beyond the classroom)

- Safe exploration (e.g. guided/facilitated instruction by a faculty person, step outside of personal comfort zones and push selfboundaries)

- Cultural (e.g. language and cultural challenges)

- Personal Growth (e.g. consolidation of a less self-centered perspective)

\section{Methods for Phase II}

During Phase II the researchers explored a broader data set collected by the university's Office of International Education and compared the data with those collected during Phase 1. In 2012, 2013, and 2014, a broader sample of pre and post-departure surveys were administered to students across the institution and their responses were collected. This particular survey asked students to reflect and respond to pre-departure planning, recruitment and selection processes, and satisfaction with the overall experience. Phase II of the study received additional ethics clearance to collect data from human subjects.

\section{Data Analysis}

A total of 28 Likert items ( $1=$ strongly disagree to $5=$ strongly agree) and one binary (yes/no) question for years 2012, 2013 and 2014 were included in the data analysis. Because the destinations were different each year and the number of survey participants by destination varied substantially, it was not possible to analyze changes by destination. Overall frequencies and 
percentages by year were calculated to examine the trend changes for each question during the 3year period. A histogram was developed for the binary question.

\section{Results -- Phase II}

To answer research question \# 3, responses to Likert items (1=strongly disagree, $2=$ disagree, $3=$ neutral, $4=$ agree, and $5=$ strongly agree) are reported in Figures $1-3$. There were 15 destinations to which students traveled for the GLE. The destinations were Australia, India, Norway, Mexico, United States (Utah, Illinois, and Louisiana), the Mediterranean, Thailand, Peru, Moab, Brazil, Cook Islands, Ghana, Asia, Dominican Republic, and Honduras. In total, participants $(n=161)$ from across the university responded to the pre and post-departure surveys. Overall, students indicated agreement or strong agreement with the statement "I was adequately prepared for the global learning experience". Figure 1 represents percent agreement with the adequacy of pre-departure preparation.

\section{Figure 1. Adequacy of Preparation for the GLE}

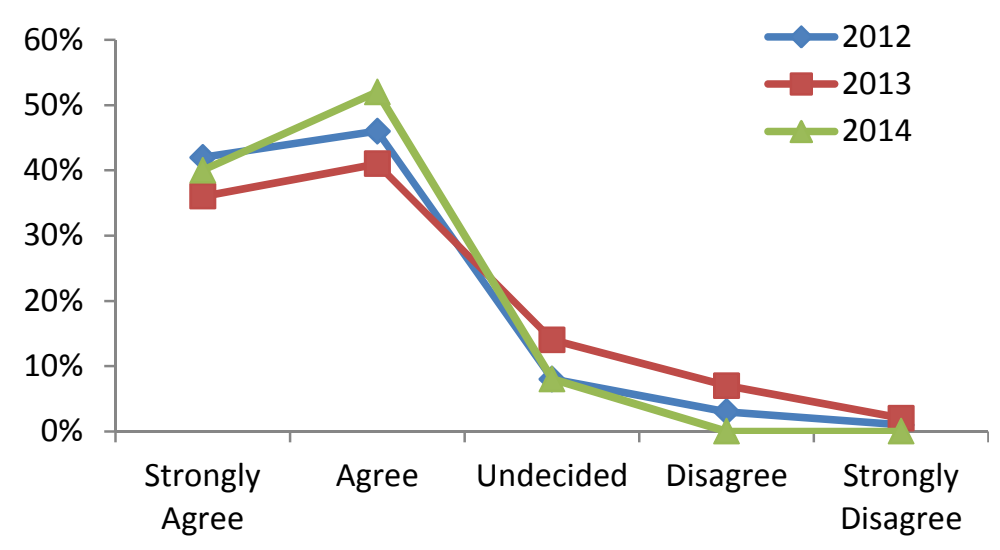

Students were also asked to indicate their level of agreement with how relevant and helpful the orientation and pre-departure preparation was to their experience. A majority of the students indicated agreement or strong agreement that the survey provided at orientation to the GLE was relevant and helpful. Figure 2 represents their cumulative responses to this item.

\section{Figure 2. Relevance and Helpfulness of Pre-Departure Orientation}

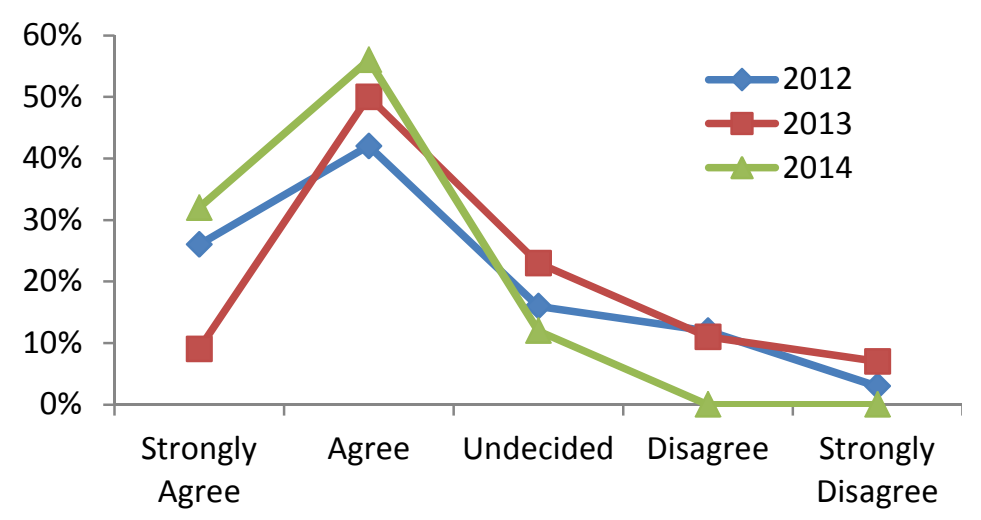


Finally, students were asked to rate their overall satisfaction with the GLE. Across the 3year period when data was collected the majority of students indicated overall satisfaction with the GLE. Figure 3 provides cumulative percent satisfaction responses.

\section{Figure 3. Overall Satisfaction with the GLE}
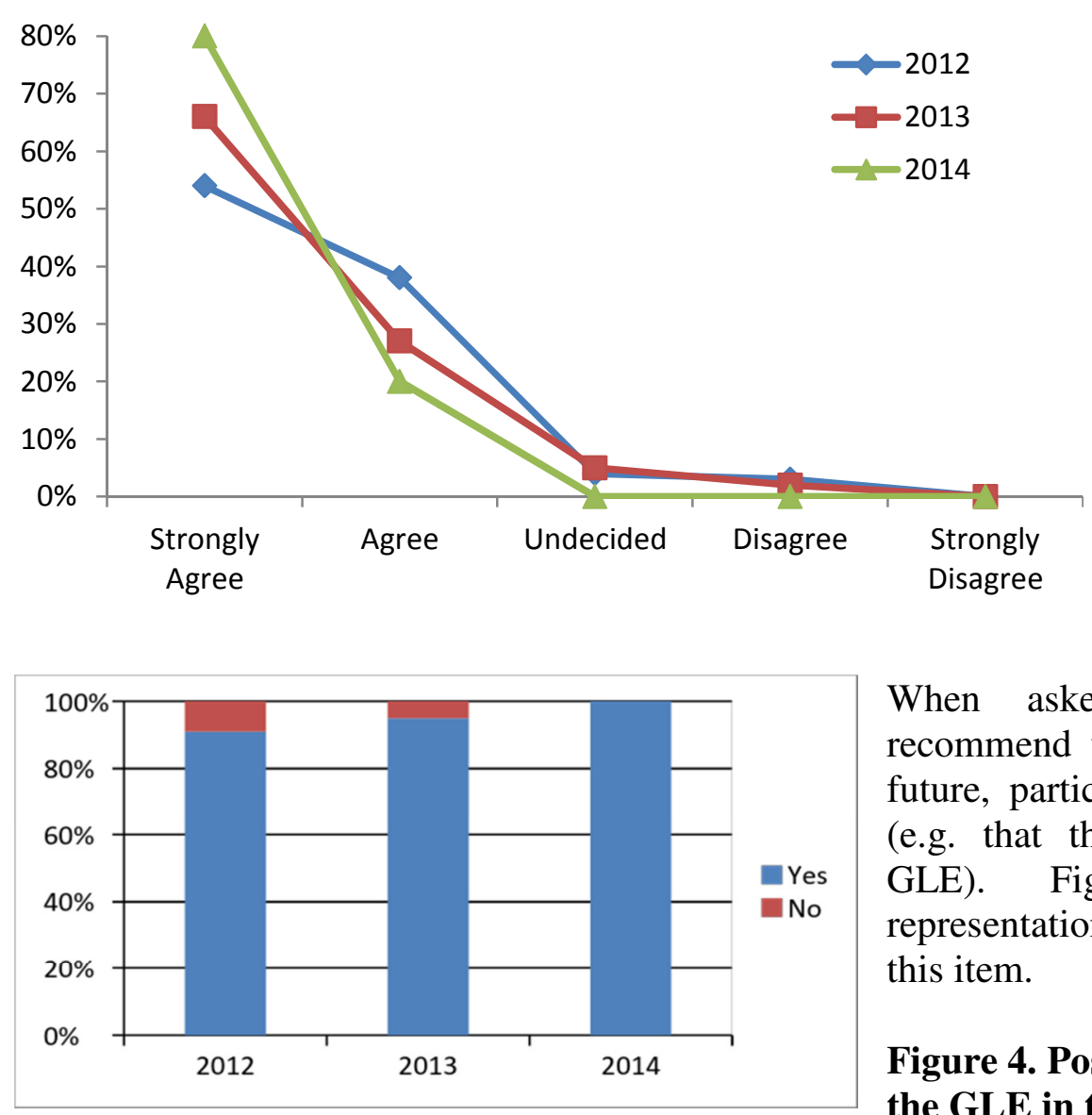

When asked whether they would recommend the GLE to students in the future, participants responded positively (e.g. that they would recommend the GLE). Figure 4 provides a visual representation of participant responses to this item.

\section{Figure 4. Positive Recommendation for} the GLE in the Future

\section{Discussion and Conclusions}

Overall results indicated that it is critical to ensure that students' expectations are grounded and realistic. Developing realistic expectations might be accomplished through adequate student preparation as part of pre-departure activities and planning sessions. One way to facilitate this process is to hold a number of pre-departure sessions with students and have them reflect on and articulate their personal and course-based expectations and share them within the group. By identifying and discussing their expectations in advance, many potential challenges are addressed and mitigated. The researchers recommend holding frequent and regular discussions with key stakeholders to minimize the occurrence of miscommunication and to ensure clear communication exchanges.

Findings from this study conclude that pre-departure preparation, orientation, and planning should begin in advance (e.g. 12-18 months prior to travel) to improve the overall GLE. One way in which expectations can be met for students is to allow sufficient "down time" during 
the GLE. This includes time to synthesize learning during the preparation phase as well as time within the GLE to rest from the rigors that accompany travel and experience in a foreign culture. Students suggested that itineraries that were completely "full" did not allow them the time to immerse themselves in the culture and "naturally" experience the GLE.

Another important consideration for faculty who would like to develop GLE is to determine whether language proficiency should be a pre-requisite for the experience. The decision to require minimum language proficiency is a complex one that requires fulsome discussion as decision makers establish selection and participation criteria. The authors recommend that whenever possible, faculty and/or student participants that are fluent in the predominant language of the host country destination participate in the GLE. Language fluency is an important consideration particularly in circumstances where safety might be a concern and where risk may need to be mitigated (e.g. there is a need to seek assistance if lost).

Group size for GLE is an oft-debated topic without clear consensus or recommendations supported in the literature. Findings in this study support smaller group size where possible to ensure that proper student supervision and individualized learning are accomplished. In many GLEs, a host organization will have specific limitations in the size of incoming cohorts to be accommodated. A relatively small group size can also enhance communication prior to and during travel. Findings suggest that the criticality of communication between students, faculty and staff who support GLE is crucial to its success.

\section{Limitations}

Students' availability for active interviews and for response validation was an additional limitation of the study. In Phase I, students participated in GLE during the spring and summer months. In the months when they were not studying they frequently worked to earn money and this often precluded them from participating in this study. These work schedules made many students unavailable for interviews or to validate responses obtained during interviews. Additionally, when they returned to the university, students' schedules often precluded them from easily participating in focus groups and completing surveys. The researchers found this to be the case and therefore made the decision to undertake individual as well as group interviews to facilitate greater participation. Due to the time constraints of students, member checking was not undertaken and might have strengthened validity of the study.

While the sample size for this study is not large, it represents a cross section of students across three years who participated in GLE. The authors believe that these responses are representative of responses obtained from students at other colleges and universities. Further, given the researchers' previous or current experience with students in a particular program of study, it is not known whether responses were provided in order to be socially desirable. In order to decrease this possibility, identification and demographic information of participants such as gender, age, and professional discipline was deliberately omitted as part of the sample description. Additional studies that include larger samples of students across multiple institutions and varied academic programs could enhance understanding of student motivations, expectations and experiences of GLE.

\section{Recommendations Based on Findings}

This research evaluated student responses on surveys distributed prior to and immediately following an international experience in Phase I and then compared data to a broader sample in 
Phase II. There are many potential and real obstacles that must be overcome when students are involved in GLE and strategies to mitigate them are emphasized in the next section. Based on findings from the two phases, the researchers propose the following key strategies:

1. Require that students critically reflect on their values, motivations, expectations and experiences at all junctures during study abroad. The opportunity for students to be guided through reflection and a critical analysis of the experience after the GLE may better support the transferability of skills and knowledge into practice in their home country (Heron 2006; Lough 2009).

2. It is also important for students who participate in GLE to share their experiences with students who did not participate because this can result in greater synthesis of learning for both groups of students.

3. Develop standardized application, recruitment, selection and orientation processes to ensure successful GLE. Selection criteria and the decision-making process must be wellpresented and take into consideration the physical, emotional, and other requirements of the activity so that students are positioned for success. User-friendly templates outlining selection processes can be developed for use across multiple GLEs being offered at an institution.

4. Faculty and administrators should meet regularly for peer learning purposes in planning and delivering GLEs.

5. Provide clear, frequent, and transparent communication with students, faculty, and key stakeholders throughout the process. It is imperative that expectations for GLE that are grounded and realistic. Students should be provided with checklists as part of predeparture planning.

6. Conduct well-organized pre-travel orientation sessions and post-travel debrief sessions that involve key stakeholders such as academic administrators, directors and managers of international education programs, students, and staff. Students should be prepared for serving their role as ambassadors of the university while representing it abroad as part of a GLE.

7. For post-secondary institutions to facilitate meaningful GLE that meet intended outcomes, institutions must ensure that sufficient resources and infrastructure are in place to support the GLE. Institutional buy-in and support for international education is crucial for sustainability of the GLE. Faculty who lead the GLE require appropriate support for developing, planning and integrating the GLE into program curricula and administrative staff must be prepared and trained for implementing pre-departure orientation programs and logistical supports.

\section{Conclusion}

While the benefits of global education and study abroad programs are many, there is limited research that identifies the motivations, expectations, and experiences of students undertaking these endeavors. Participants in the study reported here were clearly motivated to study in global settings and identified educational, social, professional, and the desire to know and understand cultures as influential factors in the decision-making process. Like most students, they expressed clear expectations for engaged, faculty-facilitated and safe learning experience in global settings. 
Participants highlighted the need for well-designed pre-departure planning and orientation sessions in order to minimize the potential challenges associated with GLE. Findings from this study are consistent with those of researchers cited earlier in this paper.

Initiatives to provide students in colleges and universities with opportunities to engage in GLE as part of their program of study show no signs of slowing down. While this study identified motivational factors, expectations, and pre-departure experiences of students, more research that evaluates how these factors impact learning outcomes in global settings over time is crucial. Future research must inform the development of best practices for GLE, particularly as the global landscape rapidly changes.

\section{REFERENCES}

Altbach, P.G., \& Knight, J. (2007). The internationalization of higher education: Motivations and realities. Journal of Studies in International Education, 11(3-4), 274-290.

Allen, H. W. (2010). What shapes short-term study abroad experiences? A comparative case study of students' motives and goals [Case study]. Journal of Studies in International Education, 14, 452-470. doi: 10.1177/1028315309334739

Altbach, P., Reisberg, L., \& Rumbley, L. (2009). Trends in global higher education: Tracking an academic revolution: A report prepared for the UNESCO 2009 world conference on higher education. Paris, France: UNESCO.

Amuzie, G., \& Winke, P. (2009). Changes in language learning beliefs as a result of study abroad. System, 37, 366-79.

Badstübner, T., \& Ecke, P. (2009). Student expectations, motivations, target language use, and perceived learning progress in a summer study abroad program in Germany. Die Unterrichtspraxis / Teaching German, 42(1), 41-49.

Belyavina, R., Li, J., \& Bhandari, R. (2013). New frontiers: U.S. students pursuing degrees abroad. A two year analysis of key destinations and fields of study. New York, NY: Institute for International Education.

Brown, L., \& Aktas, G. (2012). Turkish university students' hopes and fears about travel to the west. Journal of Research in International Education, 11(1), 3-18.

Carter, L., Horrigan, J., \& Hudyma, S. (2010). Investigating the educational needs of nurses in telepractice: A descriptive exploratory study. Canadian Journal of University Continuing Education, 36(1), 1-20.

Clarke, I., Flaherty, T. B., Wright, N. D., \& McMillen, R. M. (2009). Student intercultural proficiency from study abroad programs. Journal of Marketing Education, 31, 173-181.

Creswell, J. W. (2009). Research design: Qualitative, quantitative, and mixed methods approach. Los Angeles, CA: Sage

Creswell, J. W., Plano Clark, V. L., Gutmann, M., \& Hanson, W. (2003). Advanced mixed methods research designs. In A. Tashakkori \& C. Teddlie (Eds.), Handbook of mixed methods in social and behavioral research (pp. 209-240). Thousand Oaks, CA: Sage.

Daly, A. (2011). Determinants of participating in Australian university student exchange programs. Journal of Research in International Education, 10(1), 58-70.

Deardorff, D. K. (2008). Intercultural competence: A definition, model and implications for education abroad. In V. Savick (Ed.), Intercultural competence and transformation: Theory, research, and application international education (pp. 297-321) Sterling, VA: Stylus. 
Dwyer, M. M. (2004). More is better: The impact of study abroad program duration. Frontiers. The Interdisciplinary Journal of Study Abroad, 10, 151-163.

Farrugia, C., Bhandari, R. \& Chow, R. (2012). Open doors 2012: Report on international educational exchange. New York, NY: Institute of International Education.

Fry, G. W., Paige, R. M., Jon, J., Dillow, J., \& Nam, K. (2009). Study abroad and its transformative power. Occasional Papers on International Educational Exchange, No. 32. Retrieved from http://www.ciee.org/home/researchpublications/ documents/CIEEOccasional Papers32.pdf

Gammonley, D., Rotabi, K. S., \& Gamble, D. N. (2007). Enhancing global understanding with study abroad: Ethically grounded approaches to international learning. Journal of Teaching in Social Work, 27(3-4), 115-135. doi: 10.1300/J067v27n03_08

Gilin, B., \& Young, T. (2009). Educational benefits of international experiential learning in an MSW program. International Social Work, 52, 36-47.

Goldstein, S. B. \& Kim, R.I. (2006). Predictors of U.S. college students' participation in study abroad programs: A longitudinal study. International Journal of Intercultural Relations, 30, 507-21.

He, N., \& Chen, R. J. C. (2010). College students' perceptions and attitudes toward the selection of study abroad programs. International Journal of Hospitality \& Tourism, 11, 347-359. doi: 10.1080/15256480.2010.518525

Heron, B. (2005). Changes and challenges: Preparing social work students for practicums in today's sub-Saharan Africa context. International Social Work, 48(6), 782-793.

Ingraham, E. C., \& Peterson, D. L. (2005). Assessing the impact of study abroad on student learning at Michigan State University. Frontiers: The Interdisciplinary Journal of Study Abroad, 10(5), 83-100.

Johnson,R., \& Waterfield,J. (2004). Making words count: The value of qualitative research. Physiotherapy Research International, 9(3), 121-31.

Kruse, J., \& Brubaker, C. (2007). Successful study abroad: Tips for student preparation, immersion, and postprocessing. Die Unterrichtspraxis / Teaching German, 40(2), 14752.

Kuzma, A., Kuzma, J., \& Thiewes, H. (2012). Contrasting student attitudes toward study abroad programs among college of business majors. American Journal of Business Education, 5(4), 457-64.

Li,D. (2004). Trustworthiness of think-aloud protocols in the study of translation process. International Journal of Applied Linguistics, 14(3), 301-13.

Mapp, S. (2012). Effect of short-term study abroad programs on students' cultural adaptability. Journal of Social Work Education, 48(4), 727-37. doi: 10.5175/JSWE.2012.201100103

Mapp, S., McFarland, P., \& Newell, E. A. (2007). The effect of a short-term study abroad class on student' cross-cultural awareness. Journal of Baccalaureate Social Work, 13(1), 39-51.

Memmot, R. J., Converston, C., Heise, B. A., Williams, M., Maughan, E. D., Kohl, J., \& Palmer, S. (2010). Practical considerations in establishing sustainable international nursing experiences. Nursing Education Perspective, 31(5), 298-302.

Relyea, C., Cocchiara, F. K., \& Studdard, N. L. (2008). The effect of perceived value in the decision to participate in study abroad programs. Journal of Teaching in International Business, 19(4), 346-361. 
Rhodes, G., Biscarra, A., Loberg, L., \& Roller, K. (2012). Study abroad as a collaborative endeavor. About Campus, 16(6), 2-10. doi: 10.1002/abc.20081

Salisbury, M., Paulsen, M., \& Pascarella, E. (2010). To see the world or stay at home: Applying an integrated student choice model to explore the gender gap in the intent to study abroad. Research in Higher Education, 5, 615-640. doi: 10.1007/s11162-010-9171-6

Schnusenberg, O., \& de Jong, P. (2012). Predicting study abroad intentions based on the theory of planned behavior. Decision Sciences Journal of Innovative Education, 10(3), 337-61.

Schwieter, J. W., \& Kunert, S. (2012). Short-term study abroad and cultural sessions: Issues of L2 development, identity, and socialization. In P. C. Miller, J. Watze, \& M. Mantero (Eds.), Readings in language studies, Vol. 3: Critical language studies: Focusing on identity (pp.587-604). New York: International Society for Language Studies, Inc.

Stroud, A. (2010). Who plans (not) to study abroad: An examination of U.S. student intent. Journal of Studies in International Education, 14(5), 491-507.

Toncar, M., Reid, J., \& Anderson, C. (2005). Perceptions and preferences of study abroad: Do business students have different needs? Journal of Teaching in International Business, 17(1/2), 61-80.

Trilokekar, R. D., \& Rasmi, S. (2011). Student perceptions of international education and study abroad: A pilot study at York University. Intercultural Education, 226, 495-511.

Wehbi, S. (2009). Deconstructing motivations: Challenging international social work placements. International Social Work, 52(1), 48-59.

Zemach-Bersin, T. (2009). Selling the world: Study abroad marketing and the privatization of global citizenship. In R. Lewin (Ed.), The handbook of practice and research in study abroad: Higher education and the quest for global citizenship (pp. 303-320). New York: Routledge.

\section{AUTHORS}

VINCENT SALYERS, EdD, is the Interim Associate Vice President, Research at Mount Royal University. He has also been actively involved with international and service learning research in Ethiopia, Dominican Republic, Mexico, and Peru, as well research with vulnerable populations. Email: vsalyers@mtroyal.ca

CATHY CARSON, PhD, is the Chair of the Department of Child Studies and Social Work. She has actively supported faculty with the development of global learning experiences in Malaysia, New Zealand and Qatar. Email: ccarston@mtroyal.ca

YASMIN DEAN, PhD, is an associate professor of social work at Mount Royal University, Calgary, Canada. She leads a bi-annual field school to India and has also taken students on GEI's to China and the United Arab Emirates. The primary focus of her current research is on global service learning and cultural relevance in social work education. Email:ydean@mtroyal.ca

CHAD LONDON, PhD, is Dean of the Faculty of Health and Community Studies at Mount Royal University. He has developed global learning experiences for students in Mexico, Europe, USA and New Zealand. Email: clondon@mtroyal.ca 